\title{
The impacts of moisture transport on drifting snow sublimation in the saltation layer
}

\author{
Ning Huang ${ }^{1,2}$, Xiaoqing Dai ${ }^{1}$, and Jie Zhang ${ }^{1,2}$ \\ ${ }^{1}$ Key Laboratory of Mechanics on Disaster and Environment in Western China, Lanzhou University, Lanzhou 730000, China \\ ${ }^{2}$ School of Civil Engineering and Mechanics, Lanzhou University, Lanzhou 730000, China \\ Correspondence to: Ning Huang (huangn@1zu.edu.cn)
}

Received: 8 October 2015 - Published in Atmos. Chem. Phys. Discuss.: 11 February 2016

Revised: 28 May 2016 - Accepted: 31 May 2016 - Published: 20 June 2016

\begin{abstract}
Drifting snow sublimation (DSS) is an important physical process related to moisture and heat transfer that happens in the atmospheric boundary layer, which is of glaciological and hydrological importance. It is also essential in order to understand the mass balance of the Antarctic ice sheets and the global climate system. Previous studies mainly focused on the DSS of suspended snow and ignored that in the saltation layer. Here, a drifting snow model combined with balance equations for heat and moisture is established to simulate the physical DSS process in the saltation layer. The simulated results show that DSS can strongly increase humidity and cooling effects, which in turn can significantly reduce DSS in the saltation layer. However, effective moisture transport can dramatically weaken the feedback effects. Due to moisture advection, DSS rate in the saltation layer can be several orders of magnitude greater than that of the suspended particles. Thus, DSS in the saltation layer has an important influence on the distribution and mass-energy balance of snow cover.
\end{abstract}

\section{Introduction}

Drifting snow is a special process of mass-energy transport in the hydrological cycle of snow. It not only changes the snow distribution but also results in phase changes of ice crystals into water vapor, which is known as DSS. Snow sublimation not only significantly influences the mass-energy balance of snow cover (e.g., Zhou et al., 2014) by changing surface albedo (Allison et al., 1993) and the runoff of snowmelt in cold regions (Marks and Winstral, 2001) but also has a pivotal status on moisture and heat transfer in the atmospheric boundary layer (Pomeroy and Essery, 1999; Anderson and Neff, 2008). Thus, it is of glaciological and hydrological importance (Sugiura and Ohata, 2008). In high cold areas, the reduction of snow cover may cause the surface temperature to increase in the cold season (Huang et al., 2008, 2012). The thickness of seasonally frozen ground has decreased in response to winter warming (Huang et al., 2012). However, both dust and biomass burning aerosols may impact the surface albedo when deposited on snow; soot in particular has large impacts on absorption of radiation (J. Huang et al., 2011). In addition, a large, but unknown, fraction of the snow that falls on Antarctica is removed by the wind and subsequently sublimates. Therefore, a detailed knowledge of DSS is also essential in order to understand snow cover distribution in cold high areas as well as the mass balance of the Antarctic ice sheets and, further, the global climate system (Yang et al., 2010).

In drifting snow, snow particles can experience continuous sublimation, which induces a heat flux from the surrounding air to the particle and a moisture flux in the opposite direction (Bintanja, 2001a). Thus, DSS can cause increases in humidity and cooling of the air (Schmidt, 1982; Pomeroy et al., 1993) and has an inherent self-limiting nature due to the feedback associated with the heat and moisture budgets (Déry and Yau, 1999; Groot Zwaaftink et al., 2011, 2013). On one hand, snow sublimation absorbs heat and decreases the temperature of the ambient air, which in turn reduces the saturation vapor pressure and hence the sublimation rate; on the other hand, the increment in the moisture content of the ambient air decreases the sublimation rate of drifting snow, as it is proportional to the undersaturation of the air. 
Saltation is one of the three modes of particle motion, along with suspension and creep. Among the three modes, saltation is important and the DSS in the saltation layer may constitute a significant portion of the total snow sublimation (Dai and Huang, 2014). Previous studies of DSS mostly focused on the sublimation of suspended snow, which was mainly due to the consideration that sublimation will soon vanish in the saltation layer because the feedback of DSS may lead to a saturated layer near the surface (Bintanja, 2001b). However, the field observation data of Schmidt (1982) showed that relative humidity only slightly increases during snowdrift events and the maximum humidity was far below saturation. Further studies (Groot Zwaaftink et al., 2011; Vionnet et al., 2014) also showed that the relative humidity does not reach saturation even at the lowest atmospheric level after DSS occurs. Some scientists argued that it was caused by moisture transport, such as diffusion and advection of moisture, which inevitably accompany the drifting snow process (Vionnet et al., 2014). Therefore, it is necessary to study the feedback mechanism of DSS in the saltation layer and the effect of moisture transport on it.

In this study, we followed previous researches to assume relative humidity adjacent to snow surface is saturated and ignored surface sublimation. However, the particle sublimation in saltation layer is considered by taking into account of moisture transport in different typical cases, including (1) neglecting the effects of moisture transport, (2) considering moisture transport due to both moisture diffusion and advection, and (3) considering only moisture diffusion. Here, a wind-blown snow model, balance equations for heat and moisture of an atmospheric boundary layer, and an equation for the rate of mass loss of a single ice sphere due to sublimation were combined to study the sublimation rate of drifting snow by tracking each saltating particle in drifting snow. Then, the effects of DSS on the humidity and temperature profiles, as well as the effects of diffusion and advection of moisture on DSS in the saltation layer, were explored in detail.

\section{Methods}

\subsection{Model description}

Saltation can be divided into four interactive sub-processes, i.e., aerodynamic entrainment, particle trajectories, particlebed collisions, and wind modification (N. Huang et al., 2011).

The motion equations for snow particles are (N. Huang et al., 2011)

$$
\begin{aligned}
& m_{\mathrm{p}} \frac{\mathrm{d} U_{\mathrm{p}}}{\mathrm{d} t}=F_{\mathrm{D}}\left(\frac{U_{\mathrm{f}}-U_{\mathrm{p}}}{V_{\mathrm{r}}}\right), \\
& m_{\mathrm{p}} \frac{\mathrm{d} V_{\mathrm{p}}}{\mathrm{d} t}=-W_{\mathrm{g}}+F_{\mathrm{B}}+F_{\mathrm{D}}\left(\frac{V_{\mathrm{f}}-V_{\mathrm{p}}}{V_{\mathrm{r}}}\right),
\end{aligned}
$$

$\begin{aligned} \frac{\mathrm{d} x_{\mathrm{p}}}{\mathrm{d} t} & =U_{\mathrm{p}}, \\ \frac{\mathrm{d} y_{\mathrm{p}}}{\mathrm{d} t} & =V_{\mathrm{p}},\end{aligned}$

where $m_{\mathrm{p}}$ and $W_{\mathrm{g}}$ are the mass and weight of the snow particle, respectively; $U_{\mathrm{f}}, V_{\mathrm{f}}, U_{\mathrm{p}}$, and $V_{\mathrm{p}}$ are the horizontal and vertical velocities of the airflow and snow particle, respectively; $V_{\mathrm{r}}=\sqrt{\left(U_{\mathrm{f}}-U_{\mathrm{p}}\right)^{2}+\left(V_{\mathrm{f}}-V_{\mathrm{p}}\right)^{2}}$ is the relative velocity between the airflow and snow particle; $x_{\mathrm{p}}$ and $y_{\mathrm{p}}$ are the horizontal position and vertical height of the snow particle, respectively; $F_{\mathrm{B}}=\frac{1}{6} \rho_{f} \pi D^{3} g$ and $F_{\mathrm{D}}=\frac{1}{8} C_{\mathrm{D}} \rho_{f} \pi D^{2} V_{\mathrm{r}}^{2}$ are the buoyancy force and the drag force applied on the snow particle, respectively; $\rho_{f}$ is the air density; $D$ is the diameter of the snow particle; $g$ is the acceleration of gravity; and $C_{\mathrm{D}}$ is the drag coefficient.

Within the atmospheric boundary layer, the mean horizontal wind velocity $u$ satisfies the Navier-Stokes equation (Werner, 1990). According to Prandtl's mixing length theory for the steady flow fully developed over an infinite planar bed, $u$ satisfies

$\frac{\partial}{\partial y}\left(\rho_{f} \kappa^{2} y^{2}\left|\frac{\mathrm{d} u}{\mathrm{~d} y}\right| \frac{\mathrm{d} u}{\mathrm{~d} y}\right)+F_{x}=0$,

where $x$ is the coordinate aligned with the mean wind direction, $y$ is the vertical direction, $\kappa$ is the von Karman constant, and $F_{x}$ is the force per unit volume that the snow particles exert on the fluid in the stream-wise direction and can be expressed as

$F_{x}=\sum_{i=1}^{n} m_{\mathrm{p}} a_{i}$,

where $n$ is the number of particles per unit volume of fluid at height $y$, and $a_{i}$ is the horizontal acceleration of particle $i$.

When the bed shear stress is greater than the threshold value, snow particles begin lifting off the surface. The number of aerodynamically entrained snow particles $N_{\mathrm{a}}$ is (Shao and $\mathrm{Li}, 1999$ )

$N_{\mathrm{a}}=\varsigma u_{*}\left(1-\frac{u_{* t}^{2}}{u_{*}^{2}}\right) D^{-3}$,

where $\zeta$ is a dimensionless coefficient $\left(1 \times 10^{-3}\right.$ in our simulations), $u_{*}$ is the friction velocity, and $u_{* t}$ is the threshold friction velocity. Following the previous saltation models (McEwan and Willetts, 1993), the vertical speed of all aerodynamically entrained particles is $\sqrt{2 g D}$.

The following three splash functions for drifting snow proposed by Sugiura and Maeno (2000) based on experiments are used to determine the number and motion state of the splashed particles.

$S_{\mathrm{v}}\left(e_{\mathrm{v}}\right)=\frac{1}{\beta^{\alpha} \Gamma(\alpha)} e_{\mathrm{v}}^{\alpha-1} \exp \left(-\frac{e_{\mathrm{v}}}{\beta}\right)$ 
$S_{\mathrm{h}}\left(e_{\mathrm{h}}\right)=\frac{1}{\sqrt{2 \pi \sigma^{2}}} \exp \left[-\frac{\left(e_{\mathrm{h}}-\mu\right)^{2}}{2 \sigma^{2}}\right]$

$S_{\mathrm{e}}\left(n_{\mathrm{e}}\right)={ }_{m} C_{n_{\mathrm{e}}} p^{n_{\mathrm{e}}}(1-p)^{m-n_{\mathrm{e}}}$

In Eq. (8), $S_{\mathrm{v}}$ is the probability distribution of the vertical restitution coefficient $e_{\mathrm{v}}$ (the ratio of vertical ejection velocity and vertical impact velocity), $\Gamma(\alpha)$ is the gamma function, and $\alpha$ and $\beta$ are the shape and scale parameters for the gamma distribution function. In Eq. (9), $S_{\mathrm{h}}$ is the probability distribution of the horizontal restitution coefficient $e_{\mathrm{h}}$ (the ratio of horizontal ejection velocity and horizontal impact velocity), and $\mu$ and $\sigma$ are the mean and variance, respectively. In Eq. (10), $S_{\mathrm{e}}$ is the probability distribution function of the number of ejected particles $n_{\mathrm{e}}$, a binomial distribution function with the mean $m p$ and the variance $m p(1-p)$.

The potential temperature $\theta$ and specific humidity $q$ of the ambient air satisfy the following conservation equations (considering only two dimensions):

$$
\begin{gathered}
\frac{\partial \theta}{\partial t}+u \frac{\partial \theta}{\partial x}+v \frac{\partial \theta}{\partial y}=\frac{\partial}{\partial x}\left(K_{\theta^{\prime}} \frac{\partial \theta}{\partial x}\right) \\
+\frac{\partial}{\partial y}\left(K_{\theta} \frac{\partial \theta}{\partial y}\right)+R_{1}, \\
\frac{\partial q}{\partial t}+u \frac{\partial q}{\partial x}+v \frac{\partial q}{\partial y}=\frac{\partial}{\partial x}\left(K_{q^{\prime}} \frac{\partial q}{\partial x}\right) \\
+\frac{\partial}{\partial y}\left(K_{q} \frac{\partial q}{\partial y}\right)+R_{2},
\end{gathered}
$$

where $u$ is the mean horizontal wind velocity which could be calculated by Eq. (5) and $v$ the vertical wind velocity is assumed to be zero here; $K_{\theta^{\prime}}, K_{\theta}, K_{q^{\prime}}$, and $K_{q}$ are the heat and moisture diffusivities due to molecular motion and eddy diffusivity, respectively; $R_{1}$ and $R_{2}$ are the source terms due to snow sublimation. In this study, the wind speed is parallel to the horizontal direction; moreover, we hypothesize that the temperature and specific humidity are linearly distributed along this direction. Thus, potential temperature and specific humidity will satisfy the following prognostic equations

$$
\begin{aligned}
& \frac{\partial \theta}{\partial t}=\frac{\partial}{\partial y}\left(K_{\theta} \frac{\partial \theta}{\partial y}\right)-u \frac{\partial \theta}{\partial x}-\frac{L_{\mathrm{s}} S}{\rho_{f} C}, \\
& \frac{\partial q}{\partial t}=\frac{\partial}{\partial y}\left(K_{q} \frac{\partial q}{\partial y}\right)-u \frac{\partial q}{\partial x}+\frac{S}{\rho_{f}},
\end{aligned}
$$

where $K_{\theta}=\kappa u_{*} y+K_{T}$ and $K_{q}=\kappa u_{*} y+K_{V}$ (the sum of eddy diffusivity and molecular diffusivity, respectively); $S$ is the sublimation rate summed over all particles at each height above the surface, here taken as positive for illustration purposes; $L_{\mathrm{s}}$ is the latent heat of sublimation $(2.835 \times$ $\left.10^{6} \mathrm{~J} \mathrm{~kg}^{-1}\right) ; C$ is the specific heat of air; $\frac{\partial \theta}{\partial x}$ and $\frac{\partial q}{\partial x}$ represent the horizontal gradient in temperature and specific humidity. At the edge of snow surface, we considered the effect of advection and hypothesized that the specific humidity in the study domain is linearly distributed along the horizontal direction from entrance with $q_{\text {in }}$ to outlet with $q_{\text {out }}$.
Thus, the horizontal advection of moisture can be simplified to $u\left(q_{\text {out }}-q_{\text {in }}\right) / l$, with $l$ being the length of the domain. Except for snow surface edge, the above setup may be (or partly) suitable for some heterogeneous snow surfaces, such as patchy mosaic of snow cover. Additionally, these reasons encourage us to discuss the effect of moisture advection. For the case of infinite and homogenous snow surface, we set $q_{\text {in }}=q_{\text {out }}$ to avoid advection and considered moisture transfer via molecular motion and eddy diffusivity. Besides, we set $q_{\text {in }}=q_{\text {out }}$ and $K_{q}=K_{\theta}$ to ignore effect of advection and eddy diffusivity, as a reference case. Correspondingly, similar process was actualized for $\theta$. The variation of temperature will induce some effects on velocity field, which, however, can be ignored by testing. In our study, the variation of temperature due to snow sublimation is relatively low and its effect on velocity field is very small. Thus, we did not take this effect into consideration.

The total DSS rate $Q_{\mathrm{S}}\left(\mathrm{kg} \mathrm{s}^{-1}\right)$ of the saltation layer within the computational domain is obtained by summing the mass loss of all saltating particles in the domain.

$Q_{\mathrm{S}}=\sum_{i}\left(\frac{\mathrm{d} m}{\mathrm{~d} t}\right)_{i}$,

where $\left(\frac{\mathrm{d} m}{\mathrm{~d} t}\right)_{i}$ is the mass loss rate corresponding to the $i$ th particle. At the air temperature $T$ and undersaturation $\delta(=$ $1-\mathrm{RH})$, the rate of mass change of a single particle with diameter $D$ due to sublimation is (Thorpe and Mason, 1966)

$\frac{\mathrm{d} m}{\mathrm{~d} t}=\frac{\pi D \delta}{\frac{L_{\mathrm{s}}}{K T N u}\left(\frac{L_{\mathrm{s}}}{R_{\mathrm{v}} T}-1\right)+\frac{R_{\mathrm{v}} T}{D_{v} \text { She }_{\mathrm{s}}}}$,

where $\mathrm{RH}$ is the relative humidity of air, $K$ is the molecular thermal conductivity of the atmosphere $\left(0.024 \mathrm{~J} \mathrm{~m}^{-1} \mathrm{~s}^{-1} \mathrm{~K}^{-1}\right), \quad D_{\mathrm{v}}$ is the molecular diffusivity of water vapor in the atmosphere, $R_{\mathrm{V}}$ is the gas constant for water vapor $\left(461.5 \mathrm{~J} \mathrm{~kg}^{-1} \mathrm{~K}^{-1}\right), e_{\mathrm{s}}$ is saturated vapor pressure with respect to an ice surface, and $N u$ and $S h$ are the Nusselt number and the Sherwood number, respectively, both of which are dimensionless and depend on the wind velocity and particle size (Thorpe and Mason, 1966; Lee, 1975).

$N u=S h=\left\{\begin{array}{ll}1.79+0.606 R e^{0.5} & 0.7<R e<10 \\ 1.88+0.580 R e^{0.5} & 10<\operatorname{Re}<200\end{array}\right.$,

where $\operatorname{Re}=D V_{\mathrm{r}} / v$ is the Reynolds number and $v$ is the kinematic viscosity of air.

For the purpose of comparison with the sublimation of suspended particles, the initial relative humidity profile in accordance with that of Xiao et al. (2000) is

$\mathrm{RH}=1-R_{\mathrm{S}} \ln \left(y / y_{0}\right)$,

where $y_{0}$ is roughness length and $R_{\mathrm{S}}=0.039469$. 
The conversion relation between relative humidity and specific humidity is

$q=0.622 \cdot \frac{e_{\mathrm{s}}}{p-e_{\mathrm{s}}} \cdot \mathrm{RH}$,

where $e_{\mathrm{S}}=610.78 \exp [21.78(T-273.16) /(T-7.66)]$.

The constant initial potential temperature $\theta_{0}$ is $263.15 \mathrm{~K}$ (but is $253.16 \mathrm{~K}$ in the comparison with Xiao et al., 2000) and the initial absolute temperature is

$T_{0}=\theta_{0}\left(\frac{p}{p_{0}}\right)^{0.286}$,

where $p$ is the pressure and its initial distribution is based on the hypsometric equation

$p=p_{0} \exp \left(-\frac{y g}{R_{\mathrm{d}} \theta_{0}}\right)$

where $p_{0}$ is taken as $1000 \mathrm{hPa}$ and $R_{\mathrm{d}}$ is the gas constant for dry air $\left(287.0 \mathrm{~J} \mathrm{~kg}^{-1} \mathrm{~K}^{-1}\right)$.

\subsection{Calculation procedure}

The procedure for the calculations is enumerated below.

1. The length, width, and height of the computational domain sampled from the saltation layer above the surface are $1.0,0.01$, and $1.0 \mathrm{~m}$, respectively. The initial and boundary conditions of temperature and humidity are set from Eqs. (18)-(21).

2. Snow particles are considered as spheres with diameter of $200 \mu \mathrm{m}$ and density of $910 \mathrm{~kg} \mathrm{~m}^{-3}$. According to the investigation of Nemoto and Nishimura (2001) in a cold wind tunnel, the threshold friction velocity of snow is set to be $0.21 \mathrm{~m} \mathrm{~s}^{-1}$ and the snow bed roughness $3.0 \times$ $10^{-5} \mathrm{~m}$.

3. The initial wind field is logarithmic. If the bed shear stress is greater than the threshold value, particles are entrained from their random positions on the snow surface at vertical speed $\sqrt{2 g D}$ and the number of aerodynamically entrained snow particles satisfies Eq. (7).

4. The snow particle trajectory is calculated using Eqs. (1)-(4) every $0.00001 \mathrm{~s}$ in order to obtain the velocity used in the calculation of sublimation rate and the new location of each drifting snow particle to determine whether the snow particle falls on the snow bed.

5. As the snow particles fall on the snow bed, where they impart their energy to other snow particles and splash or eject other snow particles, the velocity and angle of the ejected particles satisfy the splash functions, i.e., Eqs. (8)-(10), according to the motion state of the incident particles and the actual wind field at that time. The number of snow particles is re-counted every $0.00001 \mathrm{~s}$.

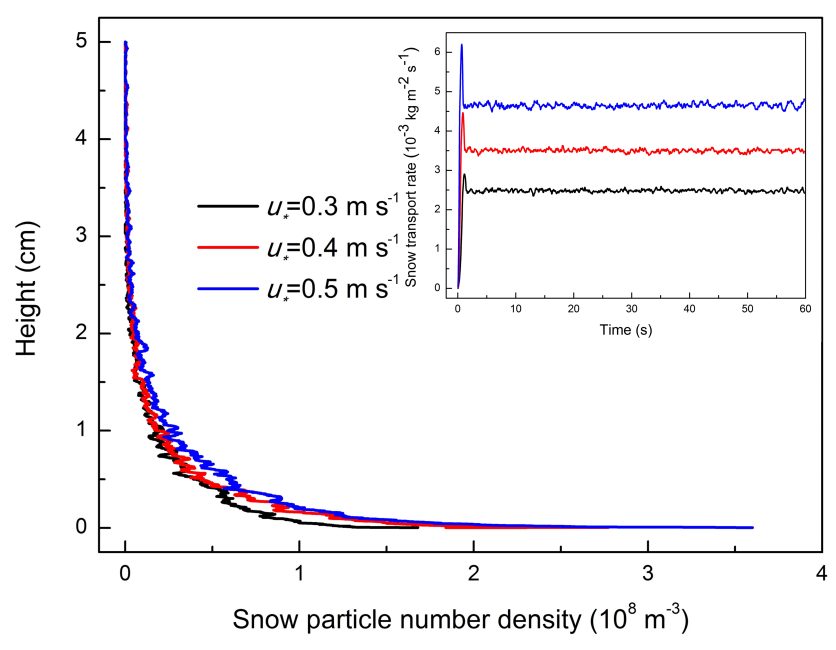

Figure 1. Temporal evolution of snow transport rate (the inset figure) and the profile of snow particle number density at the steady state for three wind force levels.

6. The reactive force $F_{x}$ that the snow particles exert on the wind field induces wind modification according to Eq. (5).

7. Based on the process above, the velocity and location of each drifting snow particle are derived and then used in Eqs. (15)-(17) to calculate their sublimation rate every $0.00001 \mathrm{~s}$. Under the effect of DSS, potential temperature and specific humidity at different heights under the diffusion or advection moisture transport are calculated every $0.00001 \mathrm{~s}$.

8. The new values of wind field calculated in step 6 are used in step 3, and then steps 4 to 7 are recalculated. Such a cycle is repeated to finish the calculation of DSS under thermodynamic effects. Each calculation takes $60 \mathrm{~s}$.

\section{Results and discussion}

\subsection{Wind-blown snow development and the structure of snow drifting}

Wind-blown snow has a self-regulating feedback mechanism between the saltating particles and the wind field; i.e., snow particles are entrained and transported by the wind, while the drag force associated with particle acceleration reduces the wind velocity in the saltation layer, thus limiting the entrainment of further particles. Figure 1 illustrates the evolution of saltating snow particles in air and also the profile of snow particle number density at steady state. The results show that the transport rate of particles in air increases rapidly and reaches a steady state after 2-3 s. In steady condition, the number of snow particles decreases with height and follows a negative 

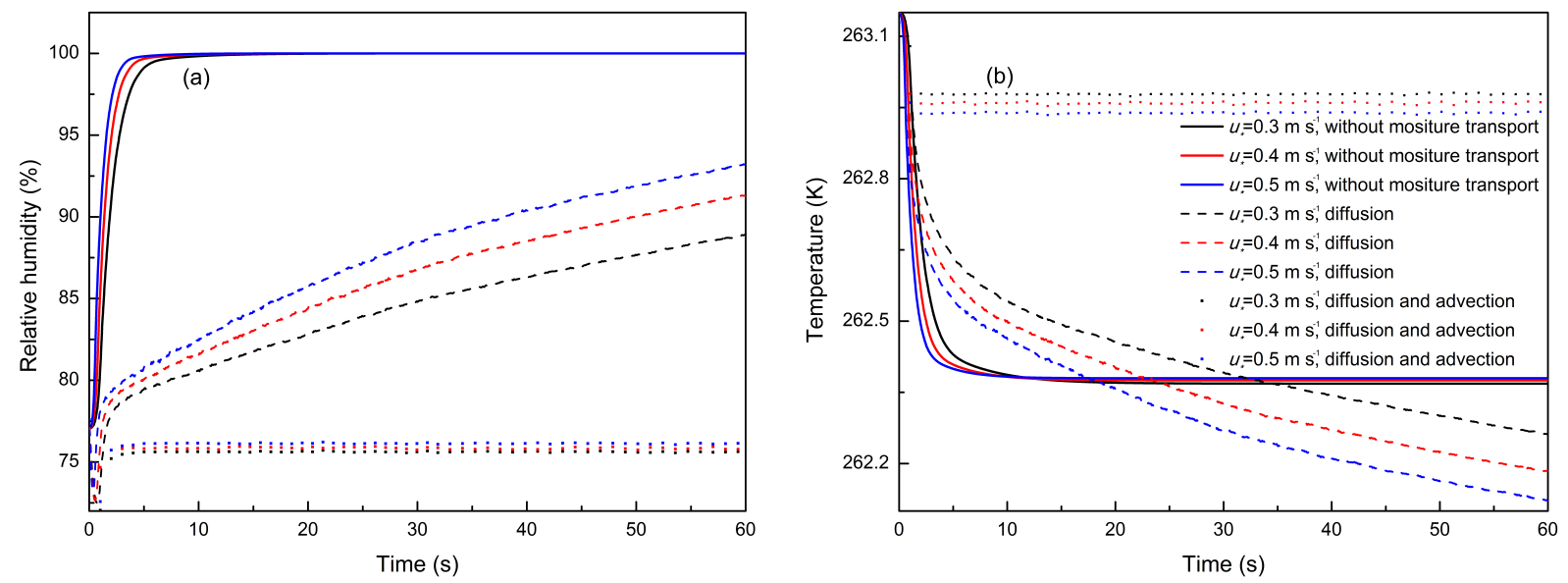

Figure 2. Temporal evolution of relative humidity (a) and temperature (b) at $1 \mathrm{~cm}$ above the surface for three wind force levels neglecting the effects of moisture transport, considering only moisture diffusion and both moisture diffusion and advection.

exponential law. Except for the particle in air, the ambient relative humidity and temperature are also important factors concern to DSS.

\subsection{Relative humidity and temperature}

The relative humidity at $1 \mathrm{~cm}$ height for different defined wind velocities generally reaches saturation within $10 \mathrm{~s}$ when moisture transport is not included (Fig. 2a). Snow sublimation will not occur, and the temperature will not change (Fig. 2b). However, when moisture transport is included, the snow sublimation occurs throughout the simulation period, and temperature decreases. Moreover, under the same moisture transport mechanism, the greater the wind friction velocity, the higher the relative humidity and temperature change (Fig. 2). The relative humidity at $1 \mathrm{~cm}$ shows a trend of rapid decrease, then rapid increase, and finally a slow increase when moisture diffusion is included (Fig. 2a), but the relative humidity does not reach saturation in the simulation period of $60 \mathrm{~s}$. Early in the wind-blown snow stage, the sublimation rate is smaller as only a few saltating particles sublime and the moisture at the lower height largely moves outwards due to the effect of moisture transport, resulting in relative humidity decrease. With continuing wind-blown snow, more snow particles leave the surface, which increases the sublimation rate and hence the relative humidity. When it reaches a steady state, the amount of snow particles in the saltation layer will no longer increase but instead fluctuate within a certain range. Thereafter, because of the increase in humidity and cooling, DSS weakens (Fig. 3). The results indicate that DSS in the saltation layer has a self-limiting nature. When the advection of moisture and heat are considered as well, the temperature and relative humidity will reach steady state finally. In this case, the transport of moisture and heat balances the change of temperature and relative humidity due to DSS.

\subsection{Sublimation rate}

From Fig. 3, we can see that DSS has reached steady state with moisture diffusion and advection considered within $60 \mathrm{~s}$, but it is not true for only moisture diffusion considered. By considering of the required time of drifting snow development and the capability of computer, the simulated time was set as $60 \mathrm{~s}$, which is significantly surpass drifting snow development time (about $2-3 \mathrm{~s}$ ) and could be actualized easily on a computer. Furthermore, the results are enough to expose the issues that we care about.

Moisture transport could remove some moisture, attenuating the increase of relative humidity and thus negative feedback, leading to higher sublimation rates with moisture transport than without (Fig. 3). With moisture removal only by diffusion, the sublimation rate at $60 \mathrm{~s}$ is roughly the same at three wind velocities, meaning that sublimation still shows obvious negative feedback. However, with moisture transport by diffusion and advection, the sublimation rate increases significantly as the negative feedback effect is effectively reduced and will reach steady state. Moreover, the sublimation rate increases with the friction velocity and can be even greater than that at the highest wind velocity without advection. For example, the sublimation rate at $60 \mathrm{~s}$ with advection is $0.88 \times 10^{-5} \mathrm{~kg} \mathrm{~m}^{-2} \mathrm{~s}^{-1}$ at a friction velocity of $0.3 \mathrm{~m} \mathrm{~s}^{-1}$, greater than that of $0.44 \times 10^{-5} \mathrm{~kg} \mathrm{~m}^{-2} \mathrm{~s}^{-1}$ at a friction velocity of $0.5 \mathrm{~m} \mathrm{~s}^{-1}$ without considering advection. The sublimation rate even reaches $1.6 \times 10^{-5} \mathrm{~kg} \mathrm{~m}^{-2} \mathrm{~s}^{-1}$, equaling the $1.38 \mathrm{~mm} \mathrm{~d}^{-1}$ snow water equivalent at a friction velocity of $0.5 \mathrm{~m} \mathrm{~s}^{-1}$ with advection included (Fig. 3). Furthermore, sublimation continues to occur. Thus, it can be seen that effective moisture transport can weaken the negative feedback of sublimation, hence significantly affecting DSS. Because the occurrence of wind-blown snow must coincide with the airflow, DSS in the saltation layer is not negligible, and the 


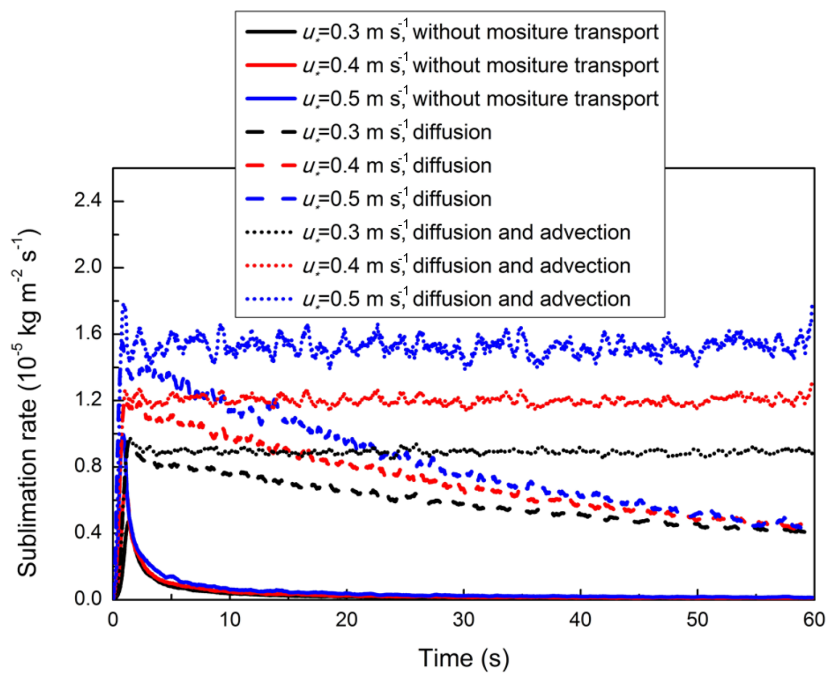

Figure 3. Temporal evolution of drifting snow sublimation rate for three wind force levels neglecting moisture transport, considering only moisture diffusion and both moisture diffusion and advection.

assumption that the saltation layer is a saturation boundary layer is inadvisable.

Air temperature decreases with decreasing height, along with air unsaturation degree during wind-blown snow, which is adverse to sublimation in contrast to higher heights above the surface. Nevertheless, the volume sublimation rate increases with decreasing height (Fig. 4). This is in agreement with the vertical profiles of the horizontal mass flux of snow particles (N. Huang et al., 2011). That is, there are more snow particles that can participate in sublimation at lower heights (Fig. 1), leading to higher sublimation rates even in environments adverse to sublimation. The results indicate that the particle number density is an important controlling factor for sublimation rate, which is consistent with a previous study (Wever et al., 2009). A comparison between our simulated results and that of four models for suspended snow, i.e., PIEKTUK-T, WINDBLAST, SNOWSTORM, and PIEKTUK-B, shows that the local sublimation rate of the suspended snow at $60 \mathrm{~s}$ can reach $10^{-6} \mathrm{~kg} \mathrm{~m}^{-3} \mathrm{~s}^{-1}$ at most (Xiao et al., 2000) (Fig. 4), smaller than that of our calculated results $\left(10^{-4}-10^{-3} \mathrm{~kg} \mathrm{~m}^{-3} \mathrm{~s}^{-1}\right)$ by $2-3$ orders of magnitude at the same initial temperature and relative humidity. This result shows that the assumption that sublimation in the saltation layer can be ignored by considering it a saturation boundary layer is inadvisable. Therefore, DSS in the saltation layer is of non-negligible importance and requires further detailed study.

\section{Conclusions}

In this study, we established a wind-blown snow model and balance equations for heat and moisture to study the effect

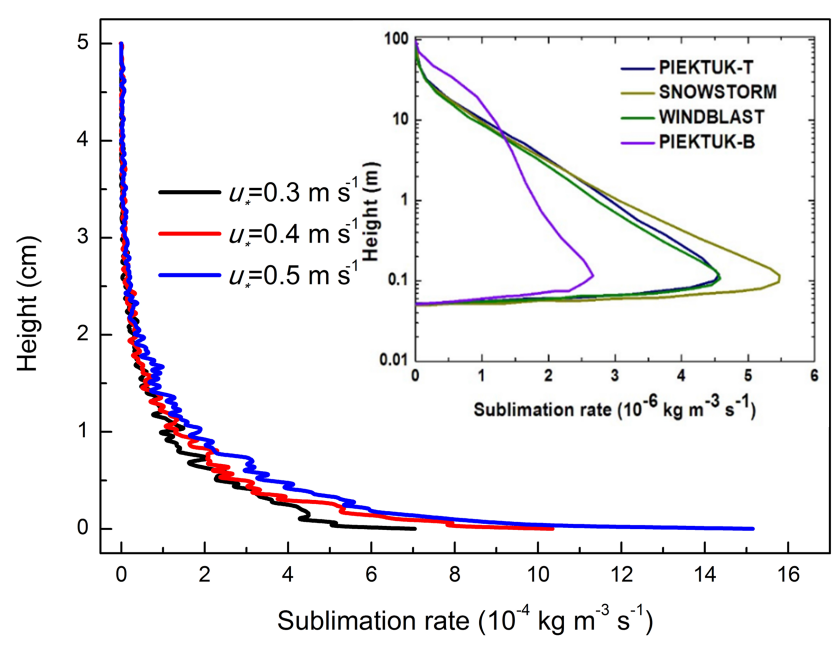

Figure 4. Comparison of the sublimation rate for the saltation layer and suspension layer (the inset figure) at $60 \mathrm{~s}$ as a function of height. The inset figure shows the sublimation rate of four models for the suspension layer with initial friction velocity of $0.87 \mathrm{~m} \mathrm{~s}^{-1}$ reported in Xiao et al. (2000). Our results for the sublimation rate in the saltation layer are obtained for three wind force levels $\left(<0.87 \mathrm{~m} \mathrm{~s}^{-1}\right)$ with moisture diffusion and advection included with the same initial temperature (253.16 K) and relative humidity as Xiao et al. (2000).

of different moisture transport mechanisms on DSS in the saltation layer. As has been reported (e.g., Schmidt, 1982), DSS could lead to strong increases in humidity and cooling, which in turn can significantly reduce the DSS rate; i.e., DSS has an inherently self-limiting nature. Moreover, the relative humidity in the saltation layer quickly reaches saturation when moisture transport is not considered. However, effective moisture transport, such as advection, can dramatically weaken the negative feedback of sublimation and prolong the duration of the higher DSS rate and hence has a profound effect on DSS. Because of the presence of advection, DSS rate increases with the friction velocity and the volume sublimation rate of saltating particles is several orders of magnitude greater than that of the suspended particles due to the higher particle density in the saltation layer. Thus, DSS in the saltation layer plays an important part in the energy and mass balance of snow cover and needs to be further studied.

\section{Data availability}

The underlying data can be found in the Supplement.

The Supplement related to this article is available online at doi:10.5194/acp-16-7523-2016-supplement. 
Acknowledgements. This work is supported by the State Key Program of National Natural Science Foundation of China (91325203), the National Natural Science Foundation of China (41371034), and Innovative Research Group of the National Natural Science Foundation of China (11421062)

Edited by: J. Huang

\section{References}

Allison, I., Brandt, R. E., and Warren, S. G., East antarctic sea ice: albedo, thickness distribution, and snow cover, J. Geophy. Res., 98, 12417-12429, 1993.

Anderson, P. S. and Neff, W. D.: Boundary layer physics over snow and ice, Atmos. Chem. Phys., 8, 3563-3582, doi:10.5194/acp-83563-2008, 2008.

Bintanja, R.: Modelling snowdrift sublimation and its effect on the moisture budget of the atmospheric boundary layer, Tellus A, 53, 215-232, 2001a.

Bintanja, R.: Snowdrift Sublimation in a Katabatic Wind Region of the Antarctic Ice Sheet, J. Appl. Meteorol., 40, 1952-1966, $2001 b$.

Dai, X. and Huang, N.: Numerical simulation of drifting snow sublimation in the saltation Layer, Sci. Rep., 4, 6611, doi:10.1038/srep06611, 2014.

Déry, S. and Yau, M.: A bulk blowing snow model, Bound.-Lay. Meteorol., 93, 237-251, 1999.

Groot Zwaaftink, C. D., Löwe, H., Mott, R., Bavay, M., and Lehning, M.: Drifting snow sublimation: A high-resolution 3-D model with temperature and moisture feedbacks, J. Geophys. Res., 116, D16107, doi:10.1029/2011jd015754, 2011.

Groot Zwaaftink, C. D., Mott, R., and Lehning, M.: Seasonal simulation of drifting snow sublimation in Alpine terrain, Water Resour. Res., 49, 1581-1590, doi:10.1002/wrcr.20137, 2013.

Huang, J., Zhang, W., Zuo, J., Bi, J., Shi, J., Wang, X., Chang, Z., Huang, Z., Yang, S., Zhang, S., Wang, G., Feng, G., Yuan, J., Zhang, L., Zuo, H., Wang, S., Fu, C., and Chou, J.: An overview of the semi-arid climate and environment research observatory over the Loess Plateau, Adv. Atmos. Sci., 25, 906-921, doi:10.1007/s00376-008-0906-7, 2008.

Huang, J., Fu, Q., Zhang, W., Wang, X., Zhang, R., Ye, H., and Warren, S.: Dust and black carbon in seasonal snow across northern China, B. Am. Meteorol. Soc., 92, 175-181, doi:10.1175/2010BAMS3064.1, 2011.

Huang, J., Guan, X., and Ji, F.: Enhanced cold-season warming in semi-arid regions, Atmos. Chem. Phys., 12, 5391-5398, doi:10.5194/acp-12-5391-2012, 2012.

Huang, N., Sang, J., and Han, K.: A numerical simulation of the effects of snow particle shapes on blowing snow development, J. Geophys. Res., 116, D22206, doi:10.1029/2011JD016657, 2011.

Lee, L.: Sublimation of snow in a turbulent atmosphere, $\mathrm{PhD}$ thesis, Univ. of Wyo., Laramie, 1975.
Marks, D. and Winstral, A.: Comparison of snow deposition, the snow cover energy balance, and snowmelt at two sites in a semiarid mountain basin, J. Hydrometeorol., 2, 213-227, 2001.

McEwan, I. K. and Willetts, B. B.: Adaptation of the near-surface wind to the development of sand transport, J. Fluid Mech., 252, 99-115, 1993.

Nemoto, M. and Nishimura, K. Direct measurement of shear stress during snow saltation, Bound.-Lay. Meteorol., 100, 149-170, 2001.

Pomeroy J. W. and Essery R. L. H.: Turbulent fluxes during blowing snow: field tests of model sublimation predictions, Hydrol Process., 13, 2963-2975, 1999.

Pomeroy, J. W., Gray, D. M., and Landine, P. G.: The Prairie Blowing Snow Model: characteristics, validation, operation, J. Hydrol., 144, 165-192, 1993.

Schmidt, R.: Vertical profiles of wind speed, snow concentration and humidity in blowing snow, Bound.-Lay. Meteorol., 23, 223246, 1982.

Shao, Y. and Li, A.: Numerical modelling of saltation in the atmospheric surface layer, Bound.-Lay. Meteorol., 91, 199-225, 1999.

Sugiura, K. and Maeno, N.: Wind-tunnel measurements of restitution coefficients and ejection number of snow particles in drifting snow: determination of splash functions, Bound.-Lay. Meteorol., 95, 123-143, 2000.

Sugiura, K. and Ohata, T.: Large-scale characteristics of the distribution of blowing-snow sublimation, Ann. Glaciol., 49, 11-16, 2008.

Thorpe, A. D. and Mason, B. J.: The evaporation of ice spheres and ice crystals, Br. J. Appl. Phys., 17, 541-548, 1966.

Vionnet, V., Martin, E., Masson, V., Guyomarc'h, G., NaaimBouvet, F., Prokop, A., Durand, Y., and Lac, C.: Simulation of wind-induced snow transport and sublimation in alpine terrain using a fully coupled snowpack/atmosphere model, The Cryosphere, 8, 395-415, doi:10.5194/tc-8-395-2014, 2014.

Werner, B. T.: A steady-state model of wind-blown sand transport, J. Geol., 98, 1-17, 1990.

Wever, N., Lehning, M., Clifton, A., Ruedi, J. D., Nishimura, K., Nemoto, M., Yamaguchi, S., and Sato, A.: Verification of moisture budgets during drifting snow conditions in a cold wind tunnel, Water Resour. Res., 45, W07423, doi:10.1029/2008WR007522, 2009.

Xiao, J., Bintanja, R., Déry, S. J., Mann, G. W., and Taylor, P. A.: An intercomparison among four models of blowing snow, Bound.Lay. Meteorol., 97, 109-135, 2000.

Yang, J., Yau, M. K., Fang, X., and Pomeroy, J. W.: A triplemoment blowing snow-atmospheric model and its application in computing the seasonal wintertime snow mass budget, Hydrol. Earth Syst. Sci., 14, 1063-1079, doi:10.5194/hess-14-10632010, 2010.

Zhou, J., Pomeroy, J. W., Zhang, W., Cheng, G., Wang, G., and Chen, C.: Simulating cold regions hydrological processes using a modular model in the west of China, J. Hydrol., 509, 13-24, 2014. 